\title{
TOWARDS A GUIDELINE OF A SPILL MANAGEMENT: INDUSTRIAL SITES AS A CASE STUDY
}

\author{
Adam Abdeljalil $^{1 *}$, Saffaj Nabil ${ }^{1}$, Mamouni Rachid ${ }^{1}$ \\ ${ }^{I *}$ University IBN ZOHR, Agadir, Morocco University, Faculty of Sciences, Laboratory \\ of Biotechnology, Materials and Environment, Marocco;
}

*Corresponding Author Adam Abdeljalil, e-mail: adam.abdeljalil@gmail.com; saffaj@gmail.com; r.mamouni@uiz.ac.m;

Received November 2021; Accepted December 2021; Published January 2022;

DOI: https://doi.org/10.31407/ijees12.117

\begin{abstract}
Industrial spills are a major environmental danger all over the world. Spill management and judgment require a comprehensive deterministic spill-event management is concerned with managing chronological and geographical unpredictability and estimates empirical hazards due to limited spill evidence. Environmental spills for the industry can be defined as unintentional discharges of hazardous gases, liquids, and solids from operations and processes, with harmful effects on flora and fauna and negative environmental consequences that require immediate care. The goal of this study is to outline spill preventative measures, contingency planning, and response requirements for industrial sites to endorse the secure reaction to leaks and spills or releases of hazardous pollutants into the environment; to remove or reduce negative impacts might a spill take place; and to safeguard health and safety of workers and neighborhood. this outlines the people and material resources provided to clean up each spill, as well as the project's reporting forms. This study intended to guarantee that, in the case of a severe leak, all required safeguards are in place to safeguard firm employees, contractors, the environment, surrounding communities, and properties. It could also be used as a starting point for the industrial site's subcontractors. Additional steps to strengthen excellent practices could be incorporated.
\end{abstract}

Keywords: Environmental spill, industry, contingency planning, leak, hazardous pollutant. 